\title{
Antinomie und Dialektik
}

Zur Funktion des Widerspruchs IN DeR Philosophie

\author{
Inaugural-Dissertation \\ zur Erlangung des Doktorgrades \\ der Philosophischen Fakultät \\ der Johann Wolfgang Goethe-Universität \\ zu Frankfurt am Main
}

\author{
vorgelegt von \\ Arend KulenkampfF \\ aus Hamburg
}


1. Gutachter: Prof. Dr. Theodor W. Adorno

2. Gutachter: Prof. Dr. Jürgen Habermas

Tag der mündlichen Prüfung: 21. 5. 1969

ISBN 978-3-476-99517-9

ISBN 978-3-476-99516-2 (eBook)

DOI 10.1007/978-3-476-99516-2 


\section{Vorbemerkung}

Philosophie ist so viel wert, wie sie durch ihre Aporien Anstoß erregt und das Denken beunruhigt. Es macht die bleibende Herausforderung Hegels aus, daß im Zentrum seiner Philosophie nicht das Postulat logischer Einstimmigkeit steht, sondern der Widerspruch. Die vorliegende Studie versteht sich als Versuch, den Sinn, der in dieser Herausforderung liegen könnte, zu entschlüsseln, ohne die aporetischen Schwierigkeiten der dialektischen Methode zu verschleiern. Zugleich sollen mögliche Alternativen angedeutet werden.

Prof. Theodor W. Adorno hat meine Arbeit durch Zuspruch und kritische Empfehlungen entscheidend gefördert. Ihm gilt mein respektvoller Dank. $\mathrm{Zu}$ danken habe ich ferner Prof. Jürgen Habermas für das Interesse, das er meinen Überlegungen entgegengebracht hat, und Prof. Wolfgang Cramer für zahlreiche Anregungen und Impulse. 


\section{Inhaltsübersicht}

\section{Über die Entstehungsbedingungen spekulativer Sätze}

I. Der Schritt in die Dialektik: Anerkennung des »Verkehrten der Wahrheit« I Begriff des Anfangs 2 - Gegenstand der philosophischen Reflexion 6 - Erkenntnistheoretische Ausgangsfrage (Natorp) 9 - Maimons Skeptizismus 12 - Programm der Spekulation 13 - Unterschied von kritischer Reflexion und Spekulation 14 - Grundsatz der Kausalität und allgemeine Erfahrungsurteile 17 - Spekulation als »Vernichtung «; systematische Sphärenvermengung 20

II (I). Bestimmung der Metaphysik (Kant) $2 I$ - „Reine Handlungen des Denkens « und Aussagen über sie 22 - Carnaps Metaphysikkriterium. Der Begriff der Konstitution 23 - Synthesis als Voraussetzung jedes sursprünglichen Sachverhalts der Erkenntnis «; Datenmannigfaltigkeiten und generelle Merkmale 26 - Fiktive Konstruktion « 28 - Poppers Kritik am Primat der Wiederholung: verschleierter Apriorismus 30 - Einheit der Erfahrung und Einheit der Welt (Husserl) 32 Der Gegenestand der philosophischen Reflexion: keine »mythische Entität« (Fichte, A. C. Danto) 34

II (2). Kategoriale Differenz im Urteil 35 - Analytische und synthetische Einheit; objektive Gültigkeit 37 - Erscheinungscharakter des Wissens 40 - Destruktion der Urteilsbeziehung 43

III (I). Vorrede zur Phänomenologie des Geistes: >wahr< und >falsch< 45 - Semantischer und traditioneller Wahrheitsbegriff 46 - Scheidung von Objekt- und Metasprache 49 - Bild und Sein (Fichte) 50 - Adäquation 52 - Urteilsanaloge Gegenstandsstruktur; Ineinssetzung und Ineinssein $54-» O b j e k t i v e$ Realität« und Wahrheit 56 - Dialektik als semantisch geschlossenes System 59

III (2). Antinomie als »formeller Ausdruck des Wissens und der Wahrheit« (Hegel) 6o - Totalität und Null-Prädikation 61 - Einheit von Urbild und Abbild 63 - Spekulativer Satz 65 - Sinndifferenz und ontische Differenzen (Cassirer) 66 Wirklichkeit als "gestuft« 68 - Fremdbezüglichkeit und Selbstbezüglichkeit 69

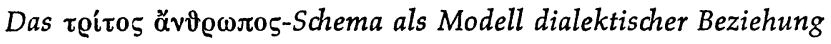

I. Unbeantwortbarkeit der Frage nach der Seinsweise der Ideen 72 - Parmenides $132 \mathrm{a}$; Analyse des Arguments 73 - Reflexion der Reflexion als systematischer »breach of logical syntax« 75 - »Schwierigkeit in der Lehre von den Ganzen«

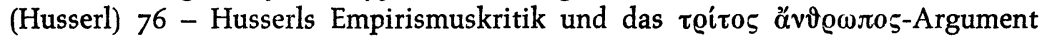
79 - Trilemma 81

II. Aporie des >Dritten $<$ und Transzendentale Dialektik 81 - Maimons Kritik 83 Die Welt als Ding an sich: Variante des naiven Platonismus 85 - Eindimensionalität oder gestuftes Gefüge 86 - Unbeschränkte und beschränkte Allgemeinheit 90 Lösung der Aporie des >Dritten<: agnostisch 91 - Sinn der Frage nach dem »Anfang « 92 - Der Totalitätsbegriff in der Kritik der reinen Vernunft 93 
III. Endlichkeit der menschlichen Vernunft 94 - „Erhebung zur Spekulation « 97 »Entgegensetzung « und ihre Aufhebung 97 - Willkürlich-experimenteller Charakter der Spekulation 98 - Methodische Voraussetzung der Phänomenologie des Geistes 101 - Hegels »absolutes Jetzt« 102 - Status der philosophischen Reflexion: Alternativen 104

Anmerkungen 106

Literaturverzeichnis 111 
Was soll denn nun die Philosophie und wozu bedarf es der spitzfindigen Zurüstungen derselben, wenn sie gesteht, daß sie für das Leben nichts Neues sagen, ja dasselbe nicht einmal als Instrument bilden kann, daß sie nur Wissenslehre, keineswegs Weisheitsschule ist?

Fichte 